\title{
Prediction of the Service Life of Metal-Polymer Gears Made of Glass and Carbon Fibre-Reinforced Polyamide, Considering the Impact of Height Correction
}

\author{
Myron Chernets ${ }^{1 *}$, Anatoliy Kornienko ${ }^{2}$ \\ 1 Department of Computerization and Robotization of Production, Lublin University of Technology, \\ Nadbystrzycka st. 36, 20-816 Lublin, Poland \\ 2 Department of Machine Science, National Aviation University, Lubomyr Huzar prosp. 1, 03680 Kiev, Ukraine \\ * Corresponding author's e-mail: m.czerniec@pollub.pl
}

\begin{abstract}
Calculation methods for predicting the service life of metal-polymer gears with height correction are proposed. Two methods for gear service life estimation are presented: a simplified method that assumes constant tooth interaction conditions and an improved method that takes into account wear-induced changes in tooth interaction conditions. Spur cylindrical gears with a steel gear and a pinion made of polyamide composite reinforced with carbon and glass fibres are studied. The effect of height correction on the service life of the gears is examined, considering the type of tooth engagement. It is established that with the improved method the service life of the gear is by up to 1.3 times longer than that calculated by the simplified method at optimal height correction coefficients. Optimal service life of the gear is achieved when the correction coefficients are $x_{1}=-x_{2}=0.1$. The effect of the coefficient of friction on gear service life is investigated. It is found that the service life of the gear with a carbon fibre-reinforced pinion is by 8.1...9.3 times longer than that of the gear with a glass fibre-reinforced pinion.
\end{abstract}

Keywords: calculation methods, metal-polymer cylindrical gear, polyamide composites, height correction, gear durability

\section{INTRODUCTION}

Gear teeth are modified to increase their load bearing capacity by reducing contact pressures. This, in turn, results in reduced wear of gear teeth and longer service life of the gear. Nevertheless, the literature of the subject offer no methods for determining the effect of addendum modification on the service life of metal and metal-polymer gears, considering both tooth engagement and tooth wear. It must be stressed that in comparison to steel, the mechanical properties of metal-polymer (MoP) gears are 10 times lower while their Young's modulus is lower from 40 to 50 times, which has a significant effect on their deformation and thus service life and wear. The calculation methods $[1,10,11,13,14,18,19,22,23]$ widely use Archard's law of adhesive/abrasive wear for metal toothed gears. However, this type of wear practically does not occur either in metal gears in maximum lubrication conditions or in metal-polymer gears in dry friction conditions.

To perform numerical calculations, one requires quantitative data regarding wear characteristics of polymeric composite materials used in MoP gears. In literature there are only few experimental studies on quantitative wear resistance of polymer reinforced composites, the results of which could be used to predict the service life and wear of MoP gears using particular calculation methods. The studies $[15,16]$ experimentally investigated the wear volume of teeth in model metal-polymer gears made of different polyamide composite materials (PA6-Mg, PA6-Na, PA66+GF-30, polyoxymethylene POM-C). These studies were conducted in dry friction and 
abrasive wear conditions. Detailed results of a wide group of polyamide composites for miniature slide bearings with different fillers are given in $[20,21]$ (without lubrication: PA6, PA66, PA66+GF30, PA66+GF50, PA66+GS28, PA610, PA11, PA12, POM-C, POM-H; with grease: PA6+GF25+graphite, PA6+GF25+MoS ${ }_{2}$. However, the experimental studies for the above-mentioned composite materials were conducted at low contact pressures and sliding velocities that are inappropriate for MoP gears. What is more, these studies did not investigate the mass wear of the composites, but identified the radial wear of journal bearings as wear characteristics. Also in [25] the author gives the results obtained for different types of polymers and polymer matrix composites (polyamides (PA), polyacetals (POM), polytetrafluoroethylenes (PTFE), polyethylenes (PE-HD, PE-UHMW), polyetheretherketones (PEEK), polyimides (PI, PEI, PAI) etc.), including tribological. Nevertheless, the linear wear rate of the above materials were determined only for single values of contact pressure and sliding velocity. Similar information can be found in brochures provided by companies manufacturing polymer composites and friction pair components. Still, the results of the above and other studies [3, 12, 17] are difficult to use as data when analysing MoP gears by the above-mentioned calculation methods, particularly the author's method. This is one of the basic reasons for not using calculation methods to predict the service life of not only metal-polymer gears but also of gears made of different polymeric compositions.

This study estimates the predicted service life of corrected MoP gears according to a modified method based on the principles of the author's calculation method [3-7] for toothed gears with metal gears. The proposed calculation method is based on the well-known phenomenological mathematical model of wear [3] at sliding friction due to friction fatigue.

\section{METHOD FOR CALCULATING GEAR SERVICE LIFE}

The predicted service life of cylindrical gears (Fig. 1) was calculated with the use of two author's methods: the simplified method [4, 5], which assumes constant contact pressures until reaching the acceptable tooth wear of one of the gears, and the improved method [6,7], which takes account of the effect of gear tooth wear on the reduction in contact pressures.

According to the simplified method $[4,5]$, where $p_{\text {jmax }}=$ const at selected $j$-th point of the tooth profile, the predicted gear service life $t_{\min }$ at which the gear teeth reach the acceptable wear $h_{k^{*}}$ is determined as follows:

$$
t_{\min }=h_{k *} / \bar{h}_{k j}
$$

The hourly rate of linear wear of the gears at contact points is here determined in an obvious way:

$$
\bar{h}_{k j}=60 n_{k} h_{k j}^{\prime}
$$

A single (relating to a single interaction of the gear teeth) linear wear $h_{k j}^{\prime}$ is determined according to the tribokinetic model of wear at sliding friction $[3,5,9]$ in the following way:

$$
h_{k j}^{\prime}=\frac{v_{j} t_{j}^{\prime}\left(f p_{j \max }\right)^{m_{k}}}{C_{k} \tau_{S}^{m_{k}}}
$$

where: $t_{j}^{\prime}=2 b_{j} / v_{0}$,

$v_{0}=\omega_{1} r_{1} \sin \alpha$,

$\tau_{S}=0.5 R_{m}-$ polymer composites

$\tau_{S}=0.35 R_{m}-$ steel.

Maximum contact pressures $p_{\text {jmax }}$ formed during meshing at $\mathrm{j}$-th contact points between the gear teeth and the contact area width $2 b_{j}$ are determined according to the Hertz equations

$$
p_{j \max }=0.564 \sqrt{N^{\prime} \theta / \rho_{j}}, 2 b_{j}=2.256 \sqrt{\theta N^{\prime} \rho_{j}}
$$

where: $N^{\prime}=N / b w$,

$$
\begin{aligned}
& N=9550 P K_{g} / r_{1} n_{1} \cos \alpha, \\
& \theta=\left(1-v_{1}^{2}\right) / E_{1}+\left(1-v_{2}^{2}\right) / E_{2}, \\
& \rho_{j}=\frac{\rho_{1 j} \rho_{2 j}}{\rho_{1 j}+\rho_{2 j}} .
\end{aligned}
$$

In spur cylindrical gears the initial curvature radii $\rho_{1 j}, \rho_{2 j}$ of the pinion teeth and gear teeth profiles are determined according to equations $(5)[3,7]$

$$
\rho_{1 j}=r_{b 1} \tan \alpha_{1 j}, \rho_{2 j}=r_{2} \sqrt{\left(r_{2 j} / r_{2}\right)^{2}-\cos ^{2} \alpha}
$$

where: $r_{b 1}=r_{1} \cos \alpha, \alpha_{1 j}=\arctan \left(\tan \alpha_{10}+j \Delta^{\bullet}\right)$,

$$
\begin{aligned}
& \tan \alpha_{10}=(1+u) \tan \alpha-\frac{u}{\cos \alpha} \sqrt{\left(r_{20} / r_{2}\right)^{2}-\cos ^{2} \alpha} \\
& r_{2}=\frac{m z_{2}}{2}, r_{20}=r_{a 2}-r, r_{a 2}=r_{2}+m, r=0,2 m \\
& \tan \alpha_{1 s}=\sqrt{\left(r_{1 s} / r_{1}\right)^{2}-\cos ^{2} \alpha}, \\
& r_{1 s}=r_{a 1}-r=r_{a 1}-0,2 m, r_{a 1}=r_{1}+m
\end{aligned}
$$


a)

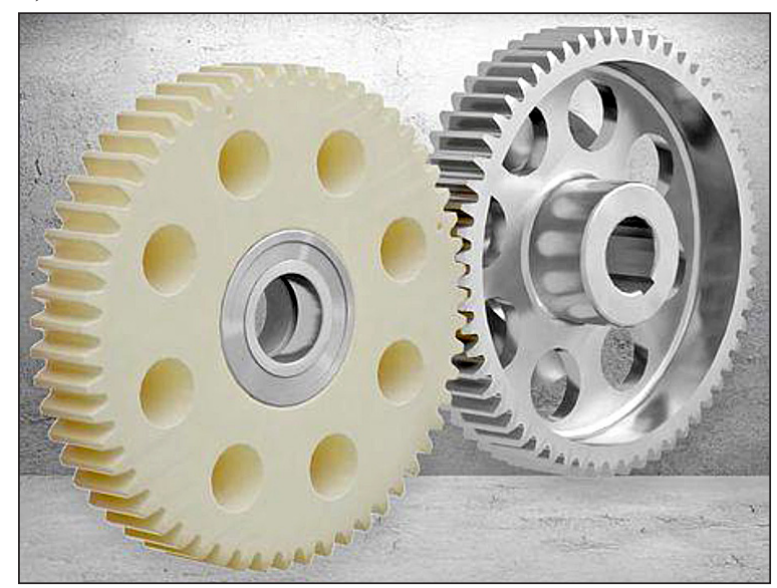

b)

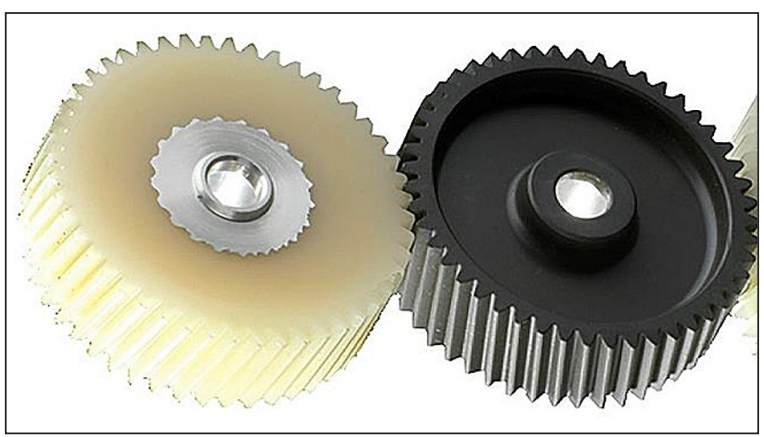

Fig. 1. Metal-polymer cylindrical gears: a) spur cylindrical gear, b) helical cylindrical gear

$$
\begin{aligned}
& r_{2 j}=\sqrt{a^{2}+r_{1 j}^{2}-2 a r_{1 j} \cos \left(\alpha-\alpha_{1 j}\right)}, \\
& a=\left(z_{1}+z_{2}\right) m / 2, r_{1 j}=r_{1} \cos \alpha / \cos \alpha_{1 j}, \\
& \cos \alpha_{20}=\frac{r_{2}}{r_{20}} \cos \alpha, \\
& \tan \alpha_{2 s}=\left(1+\frac{1}{u}\right) \tan \alpha-\frac{1}{u \cos \alpha} \sqrt{\left(\frac{r_{1 s}}{r_{1}}\right)^{2}-\cos ^{2} \alpha}
\end{aligned}
$$

According to the improved method $[6,7]$, the predicted minimum gear life $t_{B \min }$ for a specific number of gear revolutions $n_{1 s}$ and $n_{2 s}$ is calculated in the following way:

$$
t_{B \min }=n_{1 s} / 60 n_{1}=n_{2 s} / 60 n_{2}, n_{2 s}=n_{1 s} / u
$$

The number of maximum revolutions $n_{\max 1 s}$ and $n_{\max 2 s}$ is determined from the condition of reaching the acceptable gear wear $h_{k^{*}}$ at one of the contact points.

For any number of the maximum pinion revolution $n_{1 s}$ and gear revolution $n_{2 s}$, the total linear wear $h_{1 j n}$ and $h_{2 j n}$ at $j$-th point of contact will be expressed as

$$
h_{1 j n}=\sum_{1}^{n_{1 s}} h_{1 j B}, h_{2 j n}=\sum_{1}^{n_{2 s}} h_{2 j B}
$$

where: $h_{k j B}=\sum h_{k j}^{\prime}$.

Accordingly, the unit linear wear of gear teeth $h_{k j n}^{\prime}$ at any $j$-th point of contact in every single consecutive interaction is determined according to the formula (4-6):

$$
h_{k j n}^{\prime}=\frac{v_{j} t_{j h}^{\prime}\left(f p_{j h \max }\right)^{m_{k}}}{C_{k} \tau_{S}^{m_{k}}}
$$

where: $t_{j h}^{\prime}=2 b_{j h} / v_{0}$.
Sliding velocity is calculated with the equation:

$$
v_{j}=\omega_{1} r_{b 1}\left(\tan \alpha_{1 j}-\tan \alpha_{2 j}\right)
$$

where: $\alpha_{1 j}=\arctan \left(\tan \alpha_{10}+j \Delta \varphi\right)$

$$
\alpha_{2 j}=\arccos \left[\left(r_{2} / r_{2 j}\right) \cos \alpha\right]
$$

The improved method considers the effect of teeth wear on increasing the curvature radius of their profile. As a result, the initial contact pressures $p_{\text {jmax }}$ decrease while the contact area width $2 b_{j}$ increases at every $j$-th point. Thus, the values of $p_{j h \max }$ and $2 b_{j h}$ are determined according to modified Hertz equations

$p_{j h \max }=0.564 \sqrt{N^{\prime} \theta / \rho_{j h}}, 2 b_{j h}=2.256 \sqrt{\theta N^{\prime} \rho_{j h}}(10)$

where: $\rho_{j h}=\frac{\rho_{1 j h} \rho_{2 j h}}{\rho_{1 j h}+\rho_{2 j h}}$

A method for determining changes in the tooth curvature radius due to wear is described in $[3,4]$. The change in the tooth curvature radius $\rho_{k j h}$ is determined with the formula

$$
\rho_{k j h}=\rho_{k j}+\tilde{E}_{k} \sum_{B_{1}}^{B_{\max }} D_{k j B} K_{k j B}^{-1}
$$

where: $D_{k j B}=K_{k j B}^{2}$.

The proposed method uses a block-based calculation procedure. This procedure assumes that changes in the tooth curvature radii $\rho_{1 j h}$, $\rho_{2 j h}$, the reduced tooth curvature radius $\rho_{k h}$, the maximum tribocontact pressures $p_{j h \max }$ and the contact area width $2 b_{j h}$ will only be considered after a certain number of revolutions (interaction block $B)$, rather than after every single revolution (meshing cycle). In every single block, the degree of wear is calculated at constant contact 
conditions. In a successive calculation block changes in given calculation parameters are considered, and the calculations are continued with the new values of these parameters included. In effect, computational time changes proportionately to the block size. The size of an interaction block can be selected in the following way: $\mathrm{B}$ $=1$ pinion revolution - accurate solution, $\mathrm{B}=$ $10,100,1000,10000, \ldots$ revolutions or a proportionate number of pinion revolutions per 1 , $10,100,100, \ldots$ hours. The resulting wear of the gear teeth after every interaction block or after every single interaction causes changes in all computational parameters.

Wear-induced changes in the tooth profile curvature during every single block of interaction are calculated as follows:

$$
K_{k j B}=8 \sum^{B} h_{k j n}^{\prime} / l_{k j}^{2}
$$

The length of a chord replacing the involute between points $j-1, j+1$ is determined according to the following formula:

$$
l_{k j}=2 \rho_{k j h} \sin \varepsilon_{k j h}=\text { const }
$$

where: $\varepsilon_{k j h}=S_{k j} / \rho_{k j h}$

$$
\begin{aligned}
& S_{k j}=\left|\frac{m z_{k}}{4}\left(\frac{1}{\cos ^{2} \alpha_{k j}}-\frac{1}{\cos ^{2} \alpha_{k, j+1}}\right) \cos \alpha\right| \\
& \alpha_{1 j}=\arctan \left(\tan \alpha_{10}+j \Delta \varphi\right), \\
& \left.\alpha_{1, j+1}=\arctan \left(\tan \alpha_{10}+(j+1)\right) \Delta \varphi\right), \\
& \alpha_{2 j}=\arccos \left[\left(r_{2} / r_{2 j}\right) \cos \alpha\right], \\
& \alpha_{2, j+1}=\arccos \left[\left(r_{2} / r_{2, j+1}\right) \cos \alpha\right] .
\end{aligned}
$$

Spur cylindrical gears are characterized by double-single-double-pair meshing. The angles describing the shift from double to single and again double-pair meshing were determined according to $[3,7,9]$.

The method for determining the geometrical parameters of a gear with height correction $(\mathrm{P}-\mathrm{O})$ is given in [4-7]. The application of this type of modification changes the addendum circle radii of the gear and pinion teeth

$$
r_{a 1}=r_{1}+\left(1+x_{1}\right) m, \quad r_{a 2}=r_{2}+\left(1+x_{2}\right) m
$$

Other gear parameters were exactly the same as those of the unmodified gear.

\section{NUMERICAL SOLUTION, RESULTS AND DISCUSSION}

Data for calculations: $T_{\text {nom }}=4000 \mathrm{Nmm}$; $K_{g}=1.2 ; z_{1}=20 ; m=4 \mathrm{~mm} ; u=3 ; n_{1}=1000 \mathrm{rev} / \mathrm{min}$; $\Delta \stackrel{g}{\varphi}=4^{0} ; b=50 \mathrm{~mm} ; a=160 \mathrm{~mm} ; h_{1^{*}}=0.5 \mathrm{~mm}$; $f=0.2,0.3,0.4 ; B=6 \cdot 10^{6}$ revolutions ( 100 working hours); $x_{1}=-x_{2}=0,0.1,0.2,0.3,0.4$.

The metal-polymer gear with a pinion made of polymer composites and a gear made of $\mathrm{S} 45$ :

- steel: as received, grinding: $E=2.1 \cdot 10^{5} \mathrm{MPa}$, $v=0.3 ; C=10^{9}, m=2[8,9]$;

- composite 1: polyamide reinforced with $30 \%$ dispersive carbon fibres - PA6+30CF, $\tau_{S C F}=48 \mathrm{MPa}, E_{C F}=520 \mathrm{MPa}, v_{C F}=0.42$, $C_{C F}=4.7 \cdot 10^{6}, m_{C F}=2.3[8,9]$;

- composite 1: polyamide reinforced with $30 \%$ dispersive glass fibres - PA6+30GF, $\tau_{S G F}=52 \mathrm{MPa}, E_{G F}=390 \mathrm{MPa}, v_{G F}=0.42$, $C_{G F}=1.2 \cdot 10^{6}, m_{G F}=1.9[8,9]$.

Numerical results of the predicted minimal service life $t_{\min }$ (simplified method) and $t_{B \min }$ (block method) of both analysed gears when $f=0.3$ are given in Figs. 2 and 3, for the gear with a carbon-fibre reinforced pinion and the gear with a carbon fibre-reinforced pinion, respectively.

The above results demonstrate that compared to the unmodified gear, the $\mathrm{P}-\mathrm{O}$ correction has a considerable impact on the service life $t_{B \min }$ of the analysed gears. With increasing the height correction coefficients, the minimal service life of the gear reaches the highest value when $x_{1}=-x_{2}=0.1$. However, a further increase in the correction coefficients has a negative effect on the gear life. A similar relationship between increasing the height correction coefficients and $t_{\min }$ is demonstrated by the simplified method to.

At the optimal value of correction coefficients, i.e., $x_{1}=-x_{2}=0.1$, the minimal gear life determined by the simplified method is much shorter than that calculated with the improved (block) method considering a decrease in the maximum contact pressures due to pinion teeth wear.

The coefficient of friction has a significant effect on the service life of gears, as shown in Figure 4.

An analysis of the figure reveals that increasing the coefficient of friction leads to a nonlinear decrease in the service life of the investigated gears - by 3.73 times in the case of the 


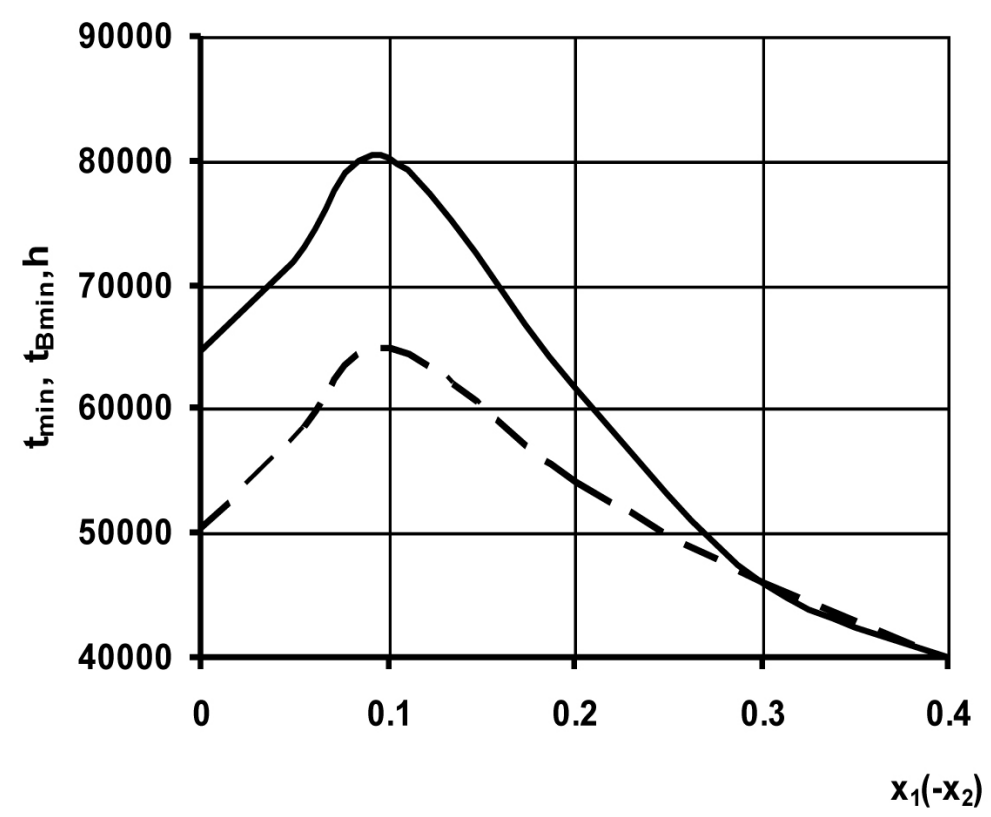

Fig. 2. Minimal service life of a metal-polymer gear (pinion - carbon fibre-reinforced polyamide / gear - steel): $t_{B \min }-$ solid line, $t_{\min }-$ dashed line

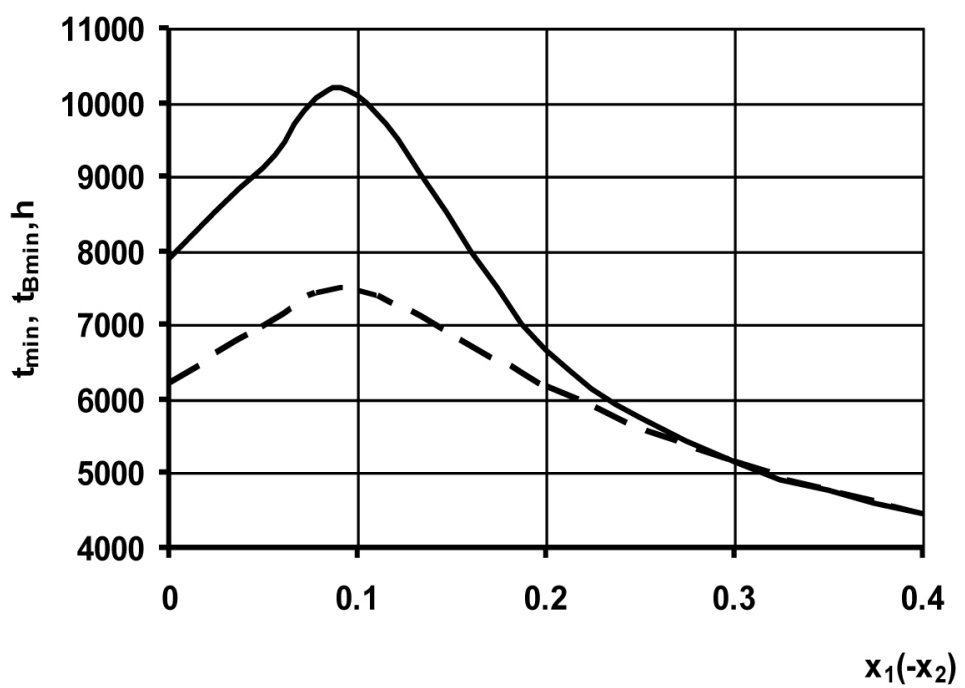

Fig. 3. Minimal service life of a metal-polymer gear (pinion - glass fibre-reinforced polyamide / gear - steel)

gear with a glass fibre-reinforced pinion and by 4.92 times in the case of the gear with a carbon fibre-reinforced pinion.

The type of fibre has a significant effect on the service life of gears. The predicted service life of the gear with carbon fibre-reinforced pinion is approx. 9 times higher than that of the gear with a glass fibre-reinforced pinion over the full range of addendum modification coefficients. Such a considerable difference in the service ls from the fact that carbon fibres have significantly higher anti-friction properties than glass fibres, the latter being characterized by higher abrasive properties.

\section{CONCLUSIONS}

By considering tooth wear in the improved method, it is possible to increase the service life of the gear by approx. 1.3 times in a certain rage of the height correction coefficients. It has been found that the predicted service life of the gear with a carbon fibre-reinforced pinion is higher by $8.1 \ldots 9.3$ times than that of the gear with a glass fibre-reinforced pinion. At the optimal value of correction coefficients, i.e., $x_{1}=-x_{2} 0.1$, the minimal gear life of both analysed gear types as estimated by the employed methods is the highest. When the correction coefficients are 


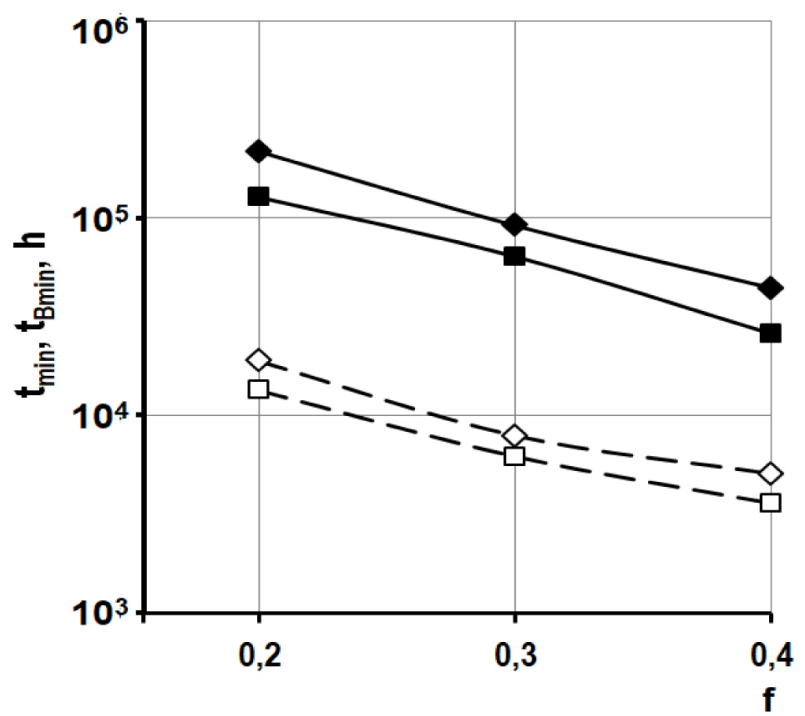

Fig. 4. Coefficient of friction versus minimal gear service life:

$t_{B \min }-$ solid line, $t_{\text {min }}-$ dashed line; $\diamond \diamond-t_{B \min }, \mathbf{\square}-t_{\min }$

$x_{1}=-x_{2}=0.16 \ldots 0.18$, the application of height correction is pointless because the service life of the gear decreases to that of the unmodified gear.

A two-fold decrease in the coefficient of friction leads to increasing the service life of the gears by 3.73 times (glass fibre-reinforced pinion) and 4.92 times (carbon fibre-reinforced pinion). The proposed method for predicting service life of metal-polymer gears allows optimization of height correction coefficients with respect to gear service life. The literature of the subject offers no such justified approach to optimized addendum modification.

\section{REFERENCES}

1. Brauer J., Andersson S. Simulation of wear in gears with flank interference - a mixed FE and analytical approach. Wear, 254, 2003, 1216-1232.

2. Cathelin J., Letzelter E., Guingand M., De Vaujany J.P., Chazeau L. Experimental and Numerical Study a Loaded Cylindrical PA66 Gear. Journal of Mechanical Design, 135, 2013, 89-98.

3. Chernets M.V., Kelbinski J., Jarema R.Ja. Generalized method for the evaluation of cylindrical involute gears. Materials Science, 1, 2011, 45-51.

4. Chernets M.V., Yarema R.Ya., Chernets Ju.M. A method for the evaluation of the influence of correction and wear of the teeth of a cylindrical gear on its durability and strength. Part 1 . Service live and wear. Materials Science, 3, 2012, 289-300.

5. Chernets M.V., Chernets Ju. M. Evaluation of the strength, wear, and durability of a corrected cylin- drical involute gearing, with due regard for the engagement conditions. Journal of Friction and Wear, 37 (1), 2016, 71-77.

6. Chernets M.V., Chernets Yu.M. A technique for calculating tribotechnical characteristics of tractive cylindrical gear of VL - 10 locomotive. Journal of Friction and Wear, 37 (6), 2017, 566-572.

7. Chernets M., Chernets Ju. The simulation of influence of engagement conditions and technological teeth correction on contact strength, wear and durability of cylindrical spur gear of electric locomotive. Proc. JMechE. Part J: Journal of Engineering Tribology, 231 (1), 2017, 57-62.

8. Chernets M.V., Shil'ko S.V., Pashechko M.I., and Barshch M. Wear resistance of glass- and carbonfilled polyamide composites for metal-polymer gears. Journal of Friction and Wear, 39 (5), 2018, 361-364.

9. Chernets M. Method of calculation of tribotechnical characteristics of the metal-polymer gear, reinforced with glass fiber, taking into account the correction of tooth // Eksploatacja i Niezawodnosc - Maintenance and Reliability, 21 (4), 2019, 546-552.

10. Flodin A., Andersson S. Wear simulation of spur gears. Tribotest J., 3(5), 1999, 225-250.

11. Flodin A., Andersson S. A simplified model for wear prediction in helical gears. Wear, 249 (3-4), 2001, 285-292.

12. Hooke C.J., Kukureka S.N. Liao P., Rao M., Chen Y.K. The Friction and Wear of Polymers in NonConformal Contacts. Wear, 200, 1996, 83-94.

13. Grib V. Solution of tribotechnical tasks with numerous methods. Science, Moscow, 1982.

14. Kahraman A., Bajpai P., Anderson N.E. Influence 
of tooth profile deviations on helical gear wear. J. Mech. Des., 127 ( 4), 2005, 656-663.

15. Kalacska G., et al. Friction and Wear of Engineering Polymer Gears. Proceedings of WTC2005 World Tribology Congress III, Sept. 12-16, 2005, Washington.

16. Keresztes R., Kalacska G. Friction of Polymer/ Steel Gear Pairs. Plastics and Rubber, 45, 2008, 236-242.

17. Kindrachuk M.V., Volchenko A.I., Volchenko D.A., Zhuravlev D.Y., Chufus V.M. Electrodynamics of the Thermal Contact Friction Interaction in Metal-Polymer Friction Couples. Material Science, 54 (1), 2018, 69-77.

18. Kolivand M., Kahraman A. An ease-off based method for loaded tooth contact analysis of hypoid gears having local and global surface deviations. J. Mech. Des., 132 (7), 2010, 0710041-0710048.

19. Pasta A., Mariotti Virzi G. Finite element method analysis of a spur gear with a corrected profile. J. Strain Analysis, 42, 2007, 281-292.
20. Rymuza Z. Predicting wear in miniature steel polymer journal bearings. Wear, 137 (2), 1990, 211-249.

21 . Rymuza Z. Tribology of polymers. Archives of civil Mechanical Engineering, 7 (4), 2007, 177-184.

22. Shil'ko S.V., Starzhinskii V.E. Prediction of Wear Resistance of Gearing with Wheels Made of Reinforced Composites. Journal of Friction and Wear, 14 (3), 1993, 7-13.

23. Shil'ko S.V., Starzhinsky V.E., Petrokovets E.M., Chernous D.A. Two-Level Calculation Method for Tribojoints Made of Disperse-Reinforced Composites: Part 1. Journal of Friction and Wear, 34 (1), 2013, 65-69.

24. Sukumaran J., et al. Modelling Gear Contact with Twin-Disc Setup. Tribology International, 49, 2012, 1-7.

25. Wielieba W. Bezobsługowe łożyska ślizgowe $\mathrm{z}$ polimerów termoplastycznych. Wyd. Politechniki Wrocławskiej, Wrocław, 2013. 